Ophthalmologica

\title{
Complete Regression of Choroidal Metastasis Secondary to Non-Small-Cell Lung Cancer with Intravitreal Bevacizumab and Oral Erlotinib Combination Therapy
}

\author{
Seong-Woo Kim ${ }^{a}$ Myung Jin Kim ${ }^{b}$ Kuhl Huha Jaeryung Oha \\ ${ }^{a}$ Department of Ophthalmology, Korea University College of Medicine, Seoul, and ${ }^{b}$ HanGil Eye Hospital, Incheon, Korea
}

\section{Key Words}

Choroidal metastasis $\cdot$ Non-small-cell lung cancer •

Bevacizumab $\cdot$ Erlotinib

\begin{abstract}
Purpose: To report a case of a complete regression of choroidal metastasis secondary to non-small-cell lung cancer (NSCLC). Methods: Retrospective case review of a female patient treated with intravitreal bevacizumab and oral erlotinib combination therapy for choroidal metastases secondary to NSCLC. Best corrected visual acuity (BCVA), fluorescein angiography (FA), optical coherence tomography (OCT), and Bscan ultrasonography were compared during the 4-month treatment period. Results: Four weeks after the third injection of bevacizumab $(2.5 \mathrm{mg})$, the BCVA had improved to 20/40 from 20/200 and the 2 subretinal masses had completely disappeared. FA demonstrated only a retinal pigment epithelial (RPE) window defect with minimal to no leakage. In the B-scan ultrasonography and OCT, no further mass-like lesion was detected. The retina and RPE layer were flattened. Conclusion: Combining intravitreal bevacizumab and oral erlotinib could be another treatment option for patients with choroidal metastasis of NSCLC.
\end{abstract}

Copyright $\odot 2009$ S. Karger AG, Base

\section{KARGER}

Fax +4161306 1234 E-Mail karger@karger.ch www.karger.com (c) 2009 S. Karger AG, Basel

$0030-3755 / 09 / 2236-0411 \$ 26.00 / 0$

Accessible online at:

www.karger.com/oph

\section{Introduction}

The most common intraocular malignancies in adults are metastatic carcinomas of the choroid. One of the most significant advances in cancer management in recent years is the development and introduction of molecularly targeted therapies, such as monoclonal antibodies and tyrosine kinase inhibitors. Some of these therapies have shown a marked ability to prolong survival without substantially increasing toxicity. In this case study, we report a case of complete regression of choroidal metastasis secondary to non-small-cell lung cancer (NSCLC) which was treated with 3 injections of intravitreal bevacizumab $(2.5 \mathrm{mg})$ and oral erlotinib combination therapy.

\section{Case Report}

A 57-year-old woman was referred to our clinic because of decreased vision in her left eye for 3 months. She had been treated with 6 cycles of docetaxel and cisplatin 6 months ago for stage IV NSCLC (adenocarcinoma) with multiple metastases. Her best-corrected visual acuity (BCVA) was 20/200 in the left eye and 20/20 in the right eye. Indirect ophthalmoscopic examination revealed $2 \mathrm{el}-$ evated choroidal masses in the superotemporal and inferotemporal quadrants of the left eye (fig. 1a, b). Subretinal fluid had accumulated around the choroidal masses. Fluorescein angiography (FA) showed multiple hyperfluorescent spots with late phase leakage (fig. 1c, d). In the B-scan ultrasonography, the retina was detached by 2 choroidal masses and subretinal fluid (fig. 1e). The size of the superior choroidal mass was $8.37 \times 7.56 \mathrm{~mm}$, and it had a thickness of $2.48 \mathrm{~mm}$. The size of the inferior choroidal mass was 7.52 

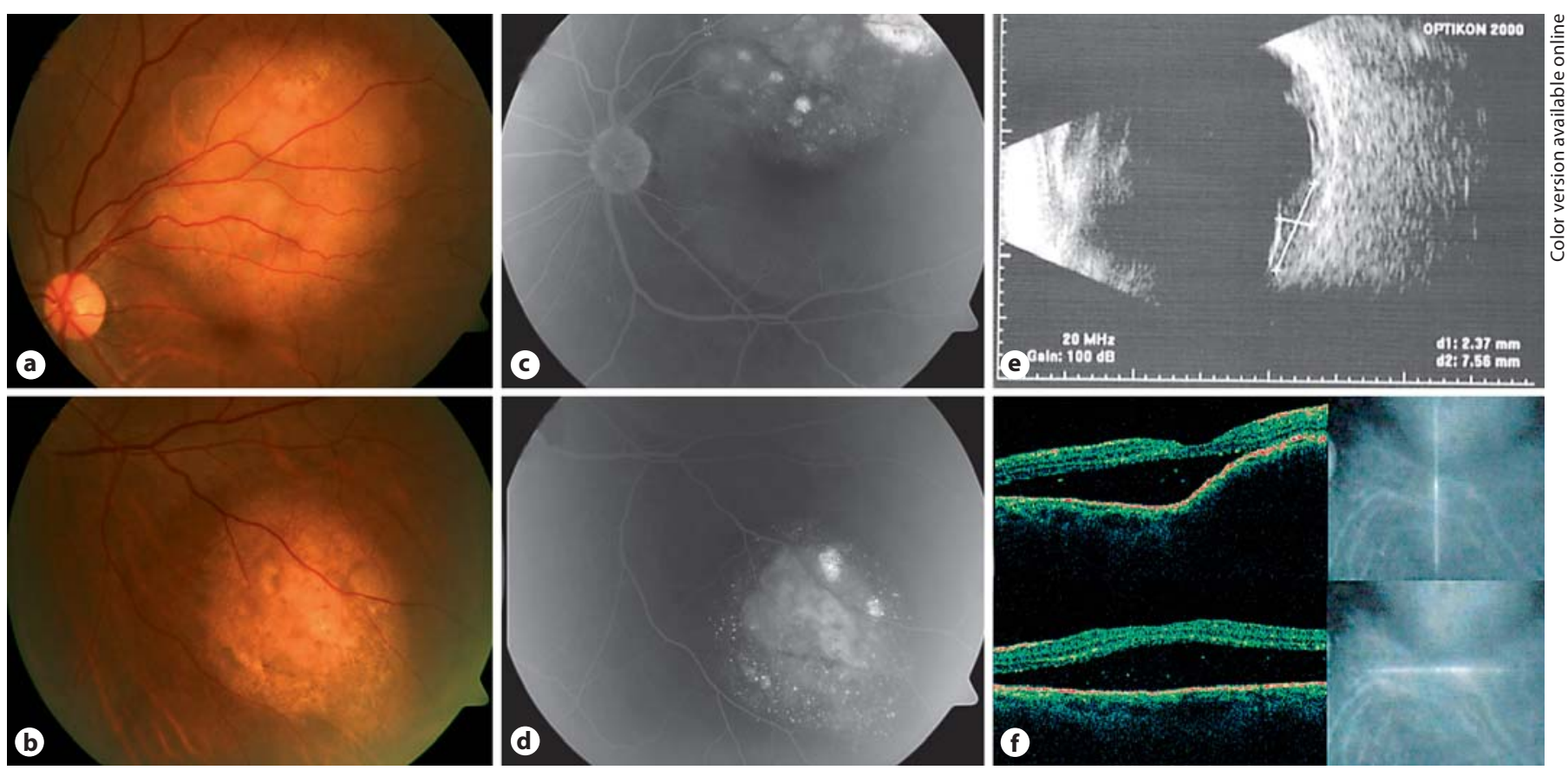

Fig. 1. Fundus photography reveals 2 elevated choroidal masses in the superotemporal and inferotemporal quadrants of the left eye $(\mathbf{a}, \mathbf{b})$. Late-phase fluorescein angiography indicates multiple hyperfluorescent spots with leakage (c, d). B-scan ultrasonography shows 2 choroidal masses. The size of the superior choroidal mass was $8.37 \times 7.56 \mathrm{~mm}$ with a thickness of $2.48 \mathrm{~mm}$. The size of the inferior choroidal mass was $7.52 \times 6.21 \mathrm{~mm}$ with a thickness of $2.94 \mathrm{~mm}(\mathbf{e})$. Serous retinal detachment and an elevated retinal pigment epithelial layer were detected with the OCT scan (f). $\times 6.21 \mathrm{~mm}$, and it had a thickness of $2.94 \mathrm{~mm}$. Optical coherence tomography (OCT) revealed sensory retinal detachment, including the fovea and elevated retinal pigment epithelial (RPE) layer (fig. 1f). A diagnosis of choroidal metastasis secondary to lung cancer was made. Bevacizumab $(2.5 \mathrm{mg})$ was injected intravitreally on 3 occasions with a 6-week interval between injections. In addition, oral erlotinib (150 mg) was prescribed daily, beginning 9 weeks after the first intravitreal bevacizumab injection.

One month after the third intravitreal bevacizumab injection, when oral erlotinib had been taken for 2 months, the BCVA had improved to 20/40, and the 2 previous masses had completely disappeared. There was a yellow and gray discoloration noted, and the retina was found to be reattached (fig. $2 \mathrm{a}, \mathrm{b}$ ). FA demonstrated only an RPE window defect with minimal to no leakage (fig. $2 \mathrm{c}$, d). No further mass-like lesion was detected on B-scan ultrasonography or OCT. The retina and RPE layer were flattened (fig. 2e, f). No ocular or systemic complications were observed at the last follow-up.

\section{Discussion}

Recently, a case of choroidal metastasis secondary to breast carcinoma was reported. This metastatic tumor was treated with a single injection of intravitreal beva- cizumab (4 mg), and partially regressed [1]. In the present case, we treated the intraocular metastatic tumor with both intravitreal bevacizumab and oral erlotinib to maximize tumor reduction and to minimize the systemic side effects of injecting bevacizumab intravitreally. Solid tumor growth and metastasis are dependent on the development of new blood vessels (neovascularization). Thus, inhibition of tumor-induced angiogenesis should prevent the growth of solid tumors and reduce the development of metastases. Vascular endothelial growth factor (VEGF) and human epidermal growth factor receptor (HER-1/EGFR) have been identified as key molecular targets for therapy in NSCLC [2]. Bevacizumab (Avastin; Genentech, South San Francisco, Calif., USA), a humanized anti-vascular endothelial growth factor monoclonal antibody, and erlotinib (Tarceva; Genentech), a reversible, orally available, highly selective epidermal grow th factor receptor tyrosine kinase inhibitor, have both demonstrated encouraging results in the treatment of NSCLC [3]. HER-1/EGFR and VEGF share common downstream signaling pathways. Erlotinib inhibits tumor cell growth and blocks the synthesis of an- 

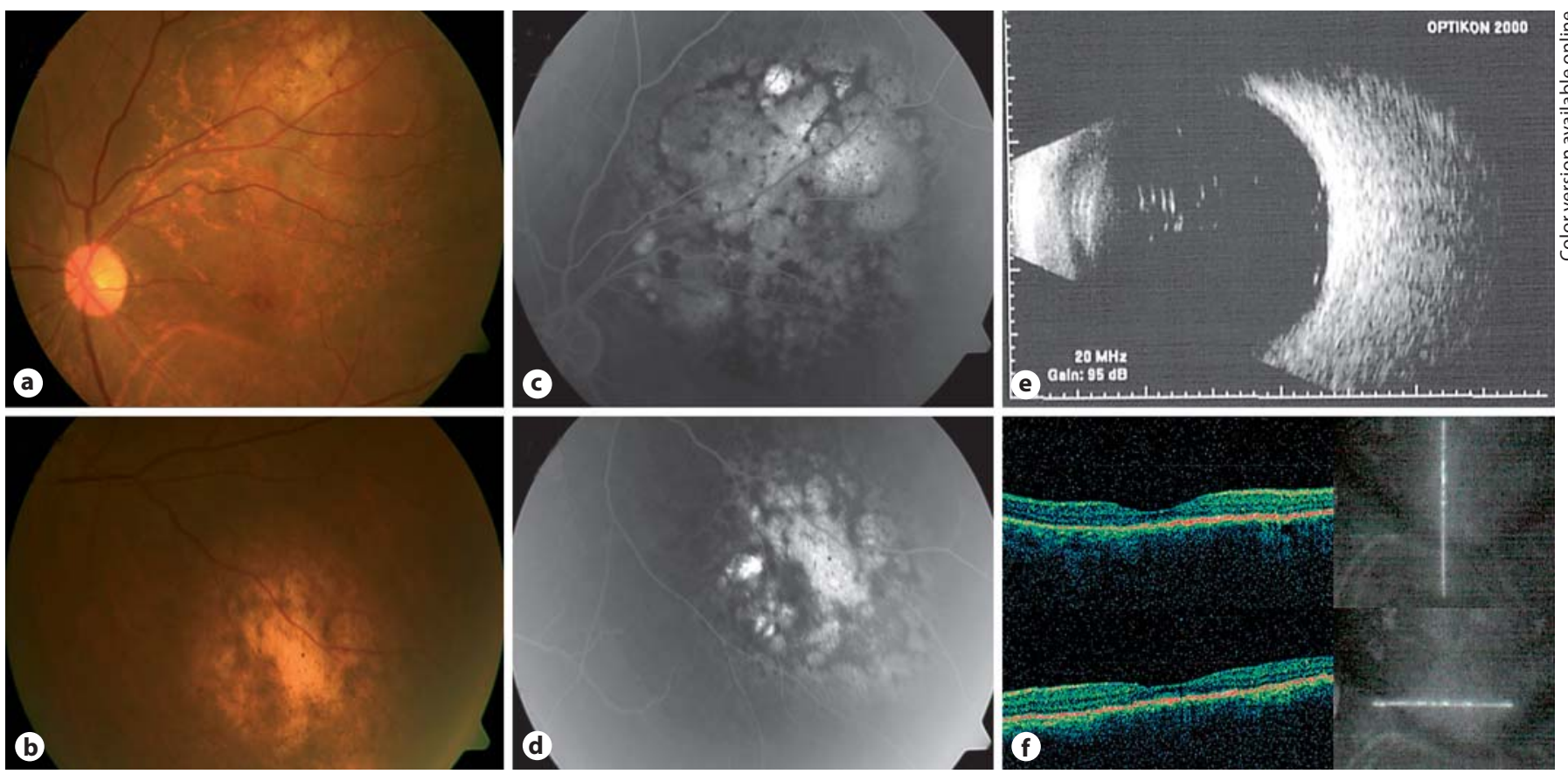

Fig. 2. In the fundus photographs 4 weeks after the third injection of bevacizumab $(2.5 \mathrm{mg})$, the 2 previous masses had completely disappeared. A yellow and gray discoloration was noted, and the retina was reattached $(\mathbf{a}, \mathbf{b})$. Late-phase fluorescein angiography

demonstrated only a retinal pigment epithelial window defect with minimal to no leakage (c, d). In the B-scan ultrasonography and OCT, no further mass-like lesion was detected. The retina and retinal pigment epithelial layer were flattened $(\mathbf{e}, \mathbf{f})$.

giogenic proteins by tumor cells, including VEGF. Bevacizumab inhibits endothelial cells from responding to the angiogenic protein VEGF. VEGF is downregulated by HER-1/EGFR inhibition [4], and blockade of VEGF may also inhibit HER-1/EGFR autocrine signaling [5]. Thus, combining these drugs to block these 2 receptors may confer additional clinical benefits as demonstrated in our patient.

In conclusion, combining intravitreal bevacizumab and oral erlotinib could be another treatment option for patients with choroidal metastasis of NSCLC.

\section{References}

- 1 Amselem L, Cervera E, Díaz-Llopis M, Montero J, Garcia-Pous M, Udaondo P, GarcíaDelpech S, Salom D: Intravitreal bevacizumab (Avastin) for choroidal metastasis secondary to breast carcinoma: short-term follow-up. Eye 2007;21:566-567.

$\checkmark 2$ Fontanini G, Vignati S, Boldrini L, Chinè S, Silvestri V, Lucchi M, Mussi A, Angeletti CA, Bevilacqua G: Vascular endothelial growth factor is associated with neovascularization and influences progression of non-small cell lung carcinoma. Clin Cancer Res 1997;3: 861-865.

3 Herbst RS, Johnson DH, Mininberg E, Carbone DP, Henderson T, Kim ES, Blumen- schein G Jr, Lee JJ, Liu DD, Truong MT, Hong WK, Tran H, Tsao A, Xie D, Ramies DA, Mass R, Seshagiri S, Eberhard DA, Kelley SK, Sandler A: Phase I/II trial evaluating the anti-vascular endothelial growth factor monoclonal antibody bevacizumab in combination with the HER-1/epidermal growth factor receptor tyrosine kinase inhibitor erlotinib for patients with recurrent nonsmall-cell lung cancer. J Clin Oncol 2005;23: 2544-2555.

-4 Petit AM, Rak J, Hung MC, Rockwell P, Goldstein N, Fendly B, Kerbel RS: Neutralizing antibodies against epidermal growth factor and ErbB2-neu receptor tyrosine ki- nase downregulate vascular endothelial growth factor production by tumor cells in vitro and in vivo. Am J Pathol 1997;151: 1523-1530.

$\checkmark 5$ Ciardiello F, Caputo R, Damiano V, Caputo $\mathrm{R}$, Troiani T, Vitagliano D, Carlomagno F, Veneziani BM, Fontanini G, Bianco AR, Tortora G: Antitumor effects of ZD6474, a small molecule vascular endothelial growth factor receptor tyrosine kinase inhibitor, with additional activity against epidermal growth factor receptor tyrosine kinase. Clin Cancer Res 2003;9:1546-1556. 